\title{
Chronic kidney disease and underdiagnosis of renal insufficiency among diabetic patients attending a hospital in Southern Ethiopia
}

Temesgen Fiseha $^{1 *}$, Mehidi Kassim² ${ }^{2}$ and Tilahun Yemane ${ }^{3}$

\begin{abstract}
Background: Diabetic patients with chronic kidney disease (CKD), as defined by a reduced glomerular filtration rate (GFR), are at greater risk for cardiovascular and renal events and mortality. The aim of this study was to determine the prevalence of CKD among diabetic patients attending a hospital in southern Ethiopia, and to assess underdiagnosis of renal insufficiency among those with normal serum creatinine.

Methods: A total of 214 randomly selected diabetics attending the follow-up clinic at Butajira hospital of southern Ethiopia participated in this study during the period from September 1 to October 31, 2013. All patients completed an interviewer-administered questionnaire and underwent clinical assessment. The simplified Modification of Diet in Renal Disease (MDRD) and Cockroft-Gault (C-G) equations were used to estimate GFR (eGFR) from serum creatinine.

Results: CKD, defined as eGFR $<60 \mathrm{ml} / \mathrm{min} / 1.73 \mathrm{~m}^{2}$, was present in $18.2 \%$ and $23.8 \%$ of the study participants according to the MDRD and Cockcroft-Gault (C-G) equations, respectively. Only $9.8 \%$ of the total participants, and 48.7\% (for the MDRD) and 37.3\% (for C-G) of those with eGFR $<60 \mathrm{ml} / \mathrm{min} / 1.73 \mathrm{~m}^{2}$ had abnormal serum creatinine values, i.e. $>1.5 \mathrm{mg} / \mathrm{dl}$. Normal serum creatinine was observed in $90.2 \%$ of participants attending the hospital. A large proportion of participants ranging from 38.9-56.5\% have shown to have mild to moderate renal insufficiency (stage 2-3 CKD) despite normal creatinine levels. CKD, eGFR $<60 \mathrm{ml} / \mathrm{min} / 1.73 \mathrm{~m}^{2}$, was found in 10.4 and $16.9 \%$ of participants with normal serum creatinine using the MDRD and C-G equations, respectively.

Conclusion: CKD is present in no less than $18 \%$ of diabetics attending the hospital, but it is usually undiagnosed. A significant number of diabetics have renal insufficiency corresponding to stages 2-3 CKD despite normal creatinine levels. Therefore, GFR should be considered as an estimate of renal insufficiency, regardless of serum creatinine levels being in normal range.
\end{abstract}

Keywords: Chronic kidney disease, Diabetes, Estimated glomerular filtration rate, Serum creatinine, Renal insufficiency

\section{Background}

Chronic kidney disease (CKD), characterized by a glomerular filtration rate (GFR) of less than $60 \mathrm{ml} / \mathrm{min} / 1.73 \mathrm{~m}^{2}$, is a common and serious complication of diabetes [1]. Health consequences are substantial, with sufferers at increased risk of all-cause and cardiovascular mortality, progression to kidney failure, cardiovascular disease (CVD) and hospitalizations [2,3]. For patients with diabetes and CKD, the

\footnotetext{
*Correspondence: temafiseha@gmail.com

'Department of Clinical Laboratory Science, College of Medicine and Health Science, Wollo University, Dessie, Ethiopia

Full list of author information is available at the end of the article
}

risk of hypertension, anemia, malnutrition, bone and mineral disorders, and retinopathy is higher as compared to patients with normal renal function $[4,5]$. There is an even higher prevalence of hypoglycemia due to decreased clearance of hypoglycemic agents or impaired renal gluconeogenesis [6].

Assessment of renal function is therefore important, as detecting CKD during its initial stages provides the opportunity for early therapeutic interventions to prevent or delay the onset of disease or complications and to improve outcomes. The GFR, an important component in the diagnosis of CKD, is accepted as the best index of 
overall kidney function [1,7]. Measurement of GFR using exogenous filtration markers such as inulin or iothalamate are the definitive measures, but none of these are practical or economical for routine use [8].

Serum creatinine ( $\mathrm{SCr}$ ) has been proposed as an endogenous marker of GFR and used most frequently to assess renal function in clinical practices. However, $\mathrm{SCr}$ level, which is affected by factors other than the GFR, is insufficiently sensitive to detect CKD on its own, and might remain in the normal range despite the renal function is significantly impaired $[9,10]$.

Currently, an estimated GFR (eGFR) derived from prediction equations has been suggested as a simple, rapid and reliable means of assessing renal function, and have been shown to be more accurate in estimating GFR at levels below $60 \mathrm{ml} / \mathrm{min} / 1.73 \mathrm{~m}^{2}[8,11,12]$. Consequently, available guidelines recommend the annual measurement of SCr for eGFR in all adults with diabetes and the use of prediction equations that incorporate patient's age, sex, race and body size for CKD diagnosis and staging renal insufficiency [1,13-15].

Despite the fact that diabetic patients are more likely to have CKD, and thus suffer extra morbidity and mortality than those without the disease [16,17]; there are virtually no published studies on the prevalence of CKD among diabetic patients in Ethiopia. More than this, many physicians relay on $\mathrm{SCr}$ as a measure of renal function rather than using for eGFR and interpret normal SCr levels as evidence of normal renal function. Therefore, the aim of this study was to estimate the prevalence of CKD among diabetic patients attending Butajira Hospital of southern Ethiopia, and to assess underdiagnosis of renal insufficiency among those with normal SCr.

\section{Methods}

From 568 registered diabetic patients, 229 random samples of people aged 18 years and above were drawn out using a table of random numbers constructed from the register. A total of 214 diabetics attending the follow-up clinic of Butajira Hospital, southern Ethiopia from September 1 to October 312013 were included in this cross sectional study. Butajira Hospital is located in Butajira town, $130 \mathrm{~km}$ mid-south of the capital city of Ethiopia, Addis Ababa. The hospital registers and treats all diagnosed diabetic patients and provides primary diabetes patient care.

The study was approved by the Research Ethics Committee of Jimma University. An informed verbal consent was taken from all the patients enrolled. Participants, who were recruited after being screened and counseled by their clinicians, were adults ( $\geq 18$ years) attending the diabetic clinic for follow-up. Patients were excluded if they were pregnant, hospitalized, have acute illnesses (fever), treated with dialysis and if they were not fasting.
During their visit participants were interviewed for collecting demographic and risk factor variables. Weight, height and blood pressure were measured at the time of the clinical examination performed. Body mass index (BMI) was calculated from weight (kg) in light clothing without shoes, and height (meters) without shoes. Obesity was defined as a BMI $\geq 30 \mathrm{~kg} / \mathrm{m}^{2}$. Blood pressure (BP) was measured using a mercury sphygmomanometer in the right upper arm in the sitting posture, after a five minute rest and three measurements were averaged to be recorded. Hypertension was defined as systolic BP $\geq 140 \mathrm{mmHg}$ or diastolic BP $\geq 90 \mathrm{mmHg}$ or use of antihypertensive medication irrespective of the BP.

A blood sample was collected in the early morning after an overnight fasting. Biochemical analysis were done on HumaStar 80 clinical chemistry analyzer (Human Diagnostics, Germany) using kits supplied by HUMAN (Human Diagnostics, Germany). Fasting serum glucose was measured by enzymatic GOD-PAP method. $\mathrm{SCr}$ was measured using Jaffe kinetic method as $\mathrm{mg} / \mathrm{dl}$ with calibration traceable to IDMS reference material NIST SRM 909B level 2.

\section{Measurement of kidney function}

Kidney function was assessed according to the simplified version of the Modification of Diet in Renal Disease $\left(\right.$ MDRD) study equation [14]: $186 \times \mathrm{SCr}(\mathrm{mg} / \mathrm{dl})^{-1.154} \times$ age $(\text { years })^{-0.203} \times 0.742$ (if female) $\times 1.210$ (as our population are Africans) and the Cockcroft-Gault (C-G) equation[15] normalized for the body surface area (BSA): $(140$-age $) \times$ Weight $(\mathrm{Kg}) \times 0.86$ (if female $) \times 1.73 / 72 \times$ $\mathrm{SCr}(\mathrm{mg} / \mathrm{dl}) \times \mathrm{BSA}\left(\mathrm{m}^{2}\right)$.

All participants with eGFR $<60 \mathrm{ml} / \mathrm{min} / 1.73 \mathrm{~m}^{2}$ at the first visit were advised to have their serum checked for creatinine two weeks after the first check-up. Staging of kidney function was based on the National Kidney FoundationDisease Outcomes Quality Initiative (K/DOQI) classification. Stage $1 \mathrm{CKD}$ was defined as normal or increased eGFR (eGFR $\geq 90 \mathrm{ml} / \mathrm{min} / 1.73 \mathrm{~m}^{2}$ ). Mild, moderate, and severe renal insufficiency (RI) corresponding to stage 2, 3 and 4 CKD were defined as eGFR 60-89.9, 30-59.9, and, $15-29.9 \mathrm{ml} / \mathrm{min} / 1.73 \mathrm{~m}^{2}$, respectively. For the purposes of this study, CKD was defined as eGFR $<60 \mathrm{ml} / \mathrm{min} / 1.73 \mathrm{~m}^{2}$ (stages 3-5 CKD)[1,18].

\section{Statistical analysis}

The data was entered in to "EpiInfo version 3.1" and was analyzed using SPSS version 20.0 statistical software. Data were expressed as means \pm standard deviation (SD) or percentage. Chi-square $\left(\mathrm{x}^{2}\right)$ test was used to compare proportions. Multivariate logistic regression was used to calculate adjusted odds ratios (OR) and the corresponding $95 \%$ confidence intervals $(\mathrm{CI}) . \mathrm{P}$ value $<0.05$ was used to indicate statistical significance. 


\section{Results}

Demographic and clinical characteristics of participants A total of 214 diabetic patients participated in the study, 123(57.5\%) males, and 114 (53.3\%) type 2 diabetics. Mean age of participants was $45 \pm 14.5$ years, ranging from 19 to 90 years and $40(18.7 \%)$ of them were above 60 years old. Mean body mass index (BMI) was $25.26 \pm 4.35 \mathrm{Kg} / \mathrm{m}^{2}$, and $31(14.5 \%)$ of them were obese $\left(\mathrm{BMI} \geq 30 \mathrm{~kg} / \mathrm{m}^{2}\right)$. The mean systolic and diastolic BP of participants was $121 \pm 17$ and $79 \pm 10 \mathrm{mmHg}$, respectively and 113 (52.8\%) were hypertensive. Mean fasting serum glucose (FSG) was 172.85 \pm $84.94 \mathrm{mg} / \mathrm{dl}$. Mean serum creatinine $(\mathrm{SCr})$ was $1.07 \pm$ $0.33 \mathrm{mg} / \mathrm{dl}$. The mean eGFR values according to the MDRD and C-G equations were $96.70 \pm 35.68$ and $83.61 \pm$ $29.73 \mathrm{ml} / \mathrm{min} / 1.73 \mathrm{~m}^{2}$, respectively (Table 1 ).

Of the study participants, $18.2 \%$ by the MDRD equation and $23.8 \%$ by Cockcroft-Gault (C-G) equation had CKD (defined as eGFR $<60 \mathrm{ml} / \mathrm{min} / 1.73 \mathrm{~m}^{2}$ ). There was no patient with eGFR $<30 \mathrm{ml} / \mathrm{min} / 1.73 \mathrm{~m}^{2}$. Only $48.7 \%$ and $37.3 \%$ of participants with eGFR $<60 \mathrm{ml} / \mathrm{min} /$ $1.73 \mathrm{~m}^{2}$ according to the MDRD and C-G equation, respectively had $\mathrm{SCr}$ values $>1.5 \mathrm{mg} / \mathrm{dl}$ (the relevant range for detecting CKD [GFR $<60 \mathrm{ml} / \mathrm{min} / 1.73 \mathrm{~m}^{2}$ ]). Table 2 shows the prevalence of CKD according to the K/DOQI classification using the MDRD and C-G equations.

Table 1 Demographic and clinical characteristics of study participants $(n=214)$

\begin{tabular}{|c|c|c|}
\hline \multicolumn{3}{|l|}{ Characteristics } \\
\hline \multicolumn{2}{|l|}{ Age (year), means $\pm S D$} & $45 \pm 14.5$ \\
\hline \multirow[t]{4}{*}{ Age group, n (\%) } & 18-49 Years & $118(55.2)$ \\
\hline & 50-59 Years & $56(26.1)$ \\
\hline & 60-69 Years & $28(13.1)$ \\
\hline & $\geq 70$ Years & $12(5.6)$ \\
\hline \multirow[t]{2}{*}{ Sex, n (\%) } & Male & $123(57.5)$ \\
\hline & Female & $91(42.5)$ \\
\hline \multirow[t]{2}{*}{ Type of diabetes, n (\%) } & Type 1 & $100(46.7)$ \\
\hline & Type 2 & $114(53.3)$ \\
\hline \multirow[t]{3}{*}{ Duration of diabetes, n (\%) } & $<5$ Years & $131(61.2)$ \\
\hline & 5-9.9 Years & $48(22.4)$ \\
\hline & $\geq 10$ Years & $35(16.4)$ \\
\hline \multicolumn{2}{|c|}{ Family history kidney disease, $\mathrm{n}(\%)$} & $40(18.7)$ \\
\hline \multicolumn{2}{|c|}{ Systolic blood pressure $(\mathrm{mmHg})$, means $\pm \mathrm{SD}$} & $121 \pm 17$ \\
\hline \multicolumn{2}{|c|}{ Diastolic blood pressure $(\mathrm{mmHg})$, means $\pm \mathrm{SD}$} & $79 \pm 10$ \\
\hline \multicolumn{2}{|l|}{ Hypertension, n (\%) } & $113(52.8)$ \\
\hline \multicolumn{2}{|c|}{ Body mass index $\left(\mathrm{Kg} / \mathrm{m}^{2}\right)$, means $\pm \mathrm{SD}$} & $25.26 \pm 4.35$ \\
\hline \multicolumn{2}{|c|}{ Fasting Serum Glucose $(\mathrm{mg} / \mathrm{dl})$, means $\pm \mathrm{SD}$} & $172.85 \pm 84.94$ \\
\hline \multicolumn{2}{|c|}{ Serum Creatinine $(\mathrm{mg} / \mathrm{dl})$, means $\pm S D$} & $1.07 \pm 0.33$ \\
\hline \multicolumn{2}{|c|}{ eGFR MDRD $\left(\mathrm{ml} / \mathrm{min} / 1.73 \mathrm{~m}^{2}\right)$, means $\left.\pm \mathrm{SD}\right)$} & $96.7 \pm 35.68$ \\
\hline \multicolumn{2}{|c|}{$\operatorname{eGFR}_{\mathrm{C}-\mathrm{G}}\left(\mathrm{ml} / \mathrm{min} / 1.73 \mathrm{~m}^{2}\right)$, means $\pm \mathrm{SD}$} & $83.6 \pm 29.73$ \\
\hline
\end{tabular}

Table 2 Prevalence of CKD according to K/DOQI classification by different equations ( $n=214$ )

\begin{tabular}{|c|c|c|c|c|}
\hline Stage & Description & $\begin{array}{c}\text { eGFR }(\mathrm{ml} / \mathrm{min} / \\
\left.1.73 \mathrm{~m}^{2}\right)\end{array}$ & $\begin{array}{l}\text { MDRD } \\
\mathrm{N}(\%) \\
\end{array}$ & $\begin{array}{l}\text { Cockcroft- } \\
\text { Gault N (\%) }\end{array}$ \\
\hline 1 & Normal or high GFR & $\geq 90$ & $118(55.1)$ & $84(39.3)$ \\
\hline 2 & Mild $\downarrow G F R$ & $60-89.9$ & 57 (26.6) & 79 (36.9) \\
\hline 3 & Moderate $\downarrow$ GFR & $30-59.9$ & $37(17.3)$ & $49(22.9)$ \\
\hline $3 \mathrm{~A}$ & $\begin{array}{l}\text { Mild to moderate } \\
\downarrow \text { GFR }\end{array}$ & $45-59.9$ & $30(14.0)$ & $32(15.0)$ \\
\hline $3 B$ & $\begin{array}{l}\text { Moderate to } \\
\text { severe } \downarrow \text { GFR }\end{array}$ & $30-44.9$ & $7(3.3)$ & $17(7.9)$ \\
\hline 4 & Severe $\downarrow$ GFR & $15-29.9$ & $2(0.9)$ & $2(0.9)$ \\
\hline
\end{tabular}

An increased risk of CKD was seen with: older age (adjusted OR $=5.30$, CI 1.81-15.56); female sex (adjusted $\mathrm{OR}=3.34$, CI 1.38-8.10); longer duration of diabetes (adjusted $\mathrm{OR}=4.08$, CI 1.70-9.77); family history of kidney disease (FH-KD) (adjusted $\mathrm{OR}=3.16, \mathrm{CI}$ 1.29-7.77); obesity (adjusted OR $=2.75$, CI 1.01-7.51) and poor glucose control (high FSG) (adjusted OR $=4.65$, CI 1.6912.76) when renal function was estimated by the MDRD equation. Except for obesity and gender, the same pattern was found when $\mathrm{C}-\mathrm{G}$ formula was used. The type of diabetes was associated with an increased risk of CKD on multivariate logistic regression when using $\mathrm{C}-\mathrm{G}$ equation to assess renal function.

From the total study subjects, normal SCr was observed in 193 (90.2\%) participants. Of these, 28.5\% had mild renal insufficiency (or stage 2 CKD) and $10.4 \%$ had moderate renal insufficiency (or stage 3 CKD) despite normal SCr when renal function was estimated by the MDRD equation. When renal function was estimated using C-G equation, $39.9 \%$ and $16.6 \%$ of those with normal SCr were found to have mild and moderate renal insufficiency or stage 2 and 3 CKD, respectively (Table 3 ).

The prevalence of CKD i.e. eGFR $<60 \mathrm{ml} / \mathrm{min} / 1.73 \mathrm{~m}^{2}$ among participants with normal $\mathrm{SCr}$ increased significantly with each age category, from $1.8 \%$ for age $<49$ years to 22.2 and $66.7 \%$ for age $\geq 70$ years (all $P<0.001$ ) according to the MDRD and $\mathrm{C}-\mathrm{G}$, respectively. CKD was also higher in female participants with normal $\mathrm{SCr}$ compared

Table 3 Kidney function among participants with normal serum creatinine according to the MDRD and Cockcroft-Gault equations ( $n=193$ )

\begin{tabular}{clcc}
\hline $\begin{array}{c}\text { eGFR }(\mathbf{m l} / \mathbf{m i n} / \\
\left.\mathbf{1 . 7 3} \mathbf{~ m}^{\mathbf{2}}\right)\end{array}$ & Description & $\begin{array}{c}\text { MDRD } \\
\mathbf{N}(\%)\end{array}$ & $\begin{array}{c}\text { Cockcroft-Gault } \\
\mathbf{N}(\%)\end{array}$ \\
\hline 290 Stage 1 CKD & $\begin{array}{l}\text { Normal renal } \\
\text { function }\end{array}$ & $118(61.1)$ & $84(43.5)$ \\
60 - 89.9 Stage 2 CKD & $\begin{array}{l}\text { Mild Renal } \\
\text { Insufficiency }\end{array}$ & $55(28.5)$ & $77(39.9)$ \\
30 - 59.9 Stage 3 CKD & $\begin{array}{l}\text { Moderate Renal } \\
\text { Insufficiency }\end{array}$ & $20(10.4)$ & $32(16.6)$ \\
\hline
\end{tabular}


to males: $23.5 \%$ and $0.0 \%(P<0.001)$ by the MDRD, and $27.1 \%$ and $8.3 \%(P=0.001)$ by C-G.

Compared with patients with eGFR $\geq 60 \mathrm{ml} / \mathrm{min} / 1.73 \mathrm{~m}^{2}$, patients with eGFR $<60 \mathrm{ml} / \mathrm{min} / 1.73 \mathrm{~m}^{2}$ and normal $\mathrm{SCr}$ were older, had high BMI, fasting glucose and serum creatinine when the MDRD equation was used to assess renal function. Similarly, participants with eGFR $<60 \mathrm{ml} / \mathrm{min} /$ $1.73 \mathrm{~m}^{2}$ despite normal $\mathrm{SCr}$ levels were older, had significantly increased systolic BP, fasting glucose and $\mathrm{SCr}$ when renal function was assessed by C-G.

\section{Discussion}

As diabetics are more likely to have CKD than those without diabetics, and thus suffer extra morbidity and mortality; regular assessment of renal function allows early identification of CKD and creates the opportunity for intervention to improve adverse outcomes $[2,10,17]$. Although several studies show a high prevalence of CKD in patients with diabetics, ranging between 15.1-33.1\% $[16,19]$, this study is the first to describe the prevalence of CKD among diabetic adults in Ethiopia using equations to estimate GFR.

In this study, CKD (eGFR $<60 \mathrm{ml} / \mathrm{min} / 1.73 \mathrm{~m}^{2}$ ) was found in $18.2-23.8 \%$ participants depending on the formula used to estimate GFR, with stage 3 being dominant (from 17.3 to $22.9 \%$ ). Our prevalence estimate of CKD using the MDRD equation was higher than the US NHANES III study [16], which reported $15.1 \%$, and closer to $24.7 \%$ reported in Tanzania, sub-Sahara African study using C-G equation [20]. However, our prevalence estimate of CKD using a similar definition of eGFR was lower than that of $27.5 \%$ and $31 \%$ reported in two UK studies [17,21], and $33.1 \%$ reported in Japanese study [19]. These differences in prevalence might be because of the differences in creatinine assays and calibration or differences in case-mix.

Despite this high prevalence, many patients were undiagnosed because renal function is usually assessed according to the levels of SCr and not to estimate GFR (eGFR). Only 9.8\% of the total participants and $48.7 \%$ (for the MDRD) and $37.3 \%$ (for C-G) of those with eGFR $<60 \mathrm{ml} / \mathrm{min} /$ $1.73 \mathrm{~m}^{2}$ had $\mathrm{SCr}$ values $>1.5 \mathrm{mg} / \mathrm{dl}$ (the relevant range for detecting CKD [GFR $<60 \mathrm{ml} / \mathrm{min} / 1.73 \mathrm{~m}^{2}$ ]) [22]. In two different studies, 33 to $45.3 \%$ of diabetics with eGFR $<60 \mathrm{ml} / \mathrm{min} / 1.73 \mathrm{~m}^{2}$ have shown to have raised $\mathrm{SCr}$ $[17,21]$. Accordingly, SCr failed to detect a significant number of patients with eGFR $<60 \mathrm{ml} / \mathrm{min} / 1.73 \mathrm{~m}^{2}$.

Analyses presented here also show that, a considerable number of participants ranging from $38.9-56.5 \%$ have shown to have mild to moderate RI (stages 2-3 CKD) despite normal SCr levels. A study from Poland also reported a high prevalence of CKD up to 77\%, on the basis of eGFR (from $62.8 \%$ to $76.9 \%$ ), among diabetic patients with normal SCr [10]. In our study, CKD i.e. eGFR $<60 \mathrm{ml} / \mathrm{min} /$
$1.73 \mathrm{~m}^{2}$, was found in $10.4 \%$ (for the MDRD) and 16.9\% (for C-G) of participants with normal SCr. In the above study, $13.0 \%$ and $22.4 \%$ of diabetics with normal SCr had eGFR $<60 \mathrm{ml} / \mathrm{min} / 1.73 \mathrm{~m}^{2}$ according to the MDRD and C-G equations, respectively which is comparable to our results. Thus, depending on normal $\mathrm{SCr}$ as evidence of normal renal function will result in missing a substantial proportion of patients with RI.

Furthermore, the rate of undiagnosed CKD defined as eGFR $<60 \mathrm{ml} / \mathrm{min} / 1.73 \mathrm{~m}^{2}$ without evidence of abnormal SCr was higher in females and in the elderly. This study shows that the proportion of persons with undiagnosed CKD increased with age; account for the fact that younger people have a higher GFR than older people at the same level of SCr and may translate to late diagnosis of kidney disease. Undiagnosed CKD is also associated with high BMI, fasting glucose and serum creatinine by the MDRD equation, and with high systolic blood pressure, fasting glucose and serum creatinine by $\mathrm{C}-\mathrm{G}$ equation.

Therefore, as stressed by current guidelines $\mathrm{SCr}$ alone should not be used to assess kidney function because it fails to identify many patients whose kidney function is reduced while their $\mathrm{SCr}$ is still in the normal range $[1,13]$. As SCr is affected by several factors including age, sex, race, and body size, estimation of GFR using prediction equations is recommended to avoid the misclassification of individuals on the basis of $\mathrm{SCr}$ alone $[14,15]$. Furthermore, it has been shown that the degree of kidney dysfunction in diabetes, as assessed by the eGFR, is an independent predictor of adverse outcomes in these patents $[2,23]$.

Although several equations that estimate GFR from $\mathrm{SCr}$ have been developed, the MDRD and C-G are the commonly used in clinical practice. The MDRD equation that was developed using data from patients with established CKD as measured by ${ }^{125}$ I-iothalamate clearance adjusted for BSA is quick and easy to calculate on all patients using data routinely provided when requesting a $\mathrm{SCr}$ measurement. The equation differs from the C-G in several ways including that it does not require knowledge of the patient's weight and has been generally shown to be more precise and accurate in predicting the GFR in patients with GFR $<60 \mathrm{ml} / \mathrm{min} / 1.73 \mathrm{~m}^{2}$ [24,25]. On the contrary, the C-G equation requires normalisation for BSA, estimates creatinine clearance rather than GFR, and because of the inclusion of weight in the numerator, as a measure of muscle mass, the equation overestimates the GFR in overweight and obese diabetics [26].

Although this study is the first of its type, it has some limitations. First, proteinuria has not been included since a standardized method for measuring albuminuria was not available, thus possibly leading to underestimation of the actual prevalence of CKD. Second, calculated GFR rather than measured GFR was used to diagnose renal 
insufficiency which is not the gold standard. Third, the MDRD study equation has not been validated among Ethiopian diabetic adults. Lastly, the measurement of serum creatinine was not standardized; this might influence the performance of eGFR equations. Our study also has major strength, the diagnosis of CKD based on eGFR on multiple measures of $\mathrm{SCr}$ to establish chronicity.

\section{Conclusion}

In conclusion, this study demonstrated that CKD is present in no less than 18\% of diabetic patients attending Butajira hospital of southern Ethiopia, but it is usually undiagnosed. Furthermore, the prevalence of renal insufficiency corresponding to stages $2-3$ CKD is high in diabetics despite normal creatinine levels. Therefore, selecting appropriate methods of assessing renal function can identify an important proportion of diabetic patients that are at increased risk for cardiovascular and renal outcomes.

\section{Competing interests}

The authors declare that they have no competing interests.

\section{Authors' contributions}

TF was involved in the conception, design, analysis, interpretation, report writing and manuscript writing. MK and TY had been involved in the analysis, interpretation, report writing and manuscript writing. All authors read and approved the final manuscript version submitted for publication.

\section{Acknowledgements}

We are grateful to acknowledge Jimma University College of Public Health and Medical Sciences for providing financial assistance for the study. We also like to acknowledge data collectors and administrations of the Butajira hospital. Finally, we gratefully thank the study participants.

\section{Author details}

'Department of Clinical Laboratory Science, College of Medicine and Health Science, Wollo University, Dessie, Ethiopia. ${ }^{2}$ Department of Biomedical Science, College of Public Health \& Medical Sciences, Jimma University, Jimma, Ethiopia. ${ }^{3}$ Department of Hematology, College of Public Health \& Medical Sciences, Jimma University, Jimma, Ethiopia.

Received: 3 October 2014 Accepted: 11 December 2014 Published: 15 December 2014

\section{References}

1. National Kidney Foundation: K/DOQI Clinical Practice Guidelines for Chronic Kidney Disease: Evaluation, Classification, and Stratification. Ann Intern Med 2002, 39(2):S1-266.

2. Ninomiya T, Perkovic V, de G, Zoungas S, Pillai A, Jardine M, Patel A, Cass A, Neal B, Poulter N: Albuminuria and kidney function independently predict cardiovascular and renal outcomes in diabetes. J Am Soc Nephrol 2009, 20:1813-1821.

3. Go AS, Chertow GM, Fan D, McCulloch CE, Hsu C: Chronic Kidney Disease and the Risks of Death, Cardiovascular Events, and Hospitalization. N Engl J Med 2004, 351(13):1296-1305.

4. National Kidney Foundation: KDOQI Clinical Practice Guidelines and Clinical Practice Recommendations for Diabetes and Chronic Kidney Disease. Am J Kidney Dis 2012, 49(2):S12-S154.

5. Grandfils N, Detournay B, Attali C, Joly D, Simon D, Vergès B, Toussi $M$, Briand Y, Delaitre O: Glucose Lowering Therapeutic Strategies for Type 2 Diabetic Patients with Chronic Kidney Disease in Primary Care Setting in France: A Cross-Sectional Study. Int J Endocrinol 2013, 2013:640632.

6. Yadav SCB: Glycemic control in diabetic kidney disease patients. Clin Queries Nephrol 2012, 1(2):111-114.
7. Smith HW: Comparative physiology of the kidney. In The Kidney: Structure and Function in Health and Disease. Edited by Smith HW. New York: Oxford; 1951:520-574.

8. Lesley A, Coresh J, Greene T, Andrew S: Assessing kidney function measured and estimated glomerular filtration rate. N Engl J Med 2006, 354:2473-2483.

9. Rigalleau V, Beauvieux M, Gonzalez C, Raffaitin C, Lasseur C, Combe C, Chauveau P, Faille RD, Rigothier C, Barthe N, Gin H: Estimation of renal function in patients with diabetes. Diabetes Metab 2011, 37:359-366.

10. Bachorzewska-Gajewska H, Malyszko J, Malyszko JS, Musial W, Dobrzycki S: Undiagnosed renal impairment in patients with and without diabetes with normal serum creatinine undergoing percutaneous coronary intervention. Nephrol Carlton 2006, 11:549-554.

11. Johnson DW: Use of estimated glomerular filtration rate to assess level of kidney function. Nephrology 2005, 10:S140-S146.

12. Kramer H, Molitch ME: Screening for Kidney Disease in Adults with Diabetes. Diabetes Care 2005, 28(7):1813-1816.

13. American Diabetes Association: Standards of medical care in diabetes - 2011. Diabetes Care 2011, 34(Supp 1):S11-S61.

14. Levey A, Greene T, Kusek J, Beck G: A simplified equation to predict glomerular filtration rate from serum creatinine. J Am Soc Nephrol 2000, 11:A0828.

15. Cockcroft DW, Gault MH: Prediction of creatinine clearance from serum creatinine. Nephron 1976, 16:31-41.

16. Coresh J, Astor BC, Greene T, Eknoyan G, Levey AS: Prevalence of chronic kidney disease and decreased kidney function in the adult US population: Third National Health and Nutrition Examination Survey. Am J Kidney Dis 2003, 41:1-12.

17. New JP, Middleton RJ, Klebe B, Farmer CKT, De Lusignan S, Stevens PE, O'Donoghue DJ: Assessing the prevalence, monitoring and management of chronic kidney disease in patients with diabetes compared with those without diabetes in general practice. Diabet Med 2007, 24(4):364-369.

18. Hogan M: KDIGO conference proposes changes to CKD classification, but not to the definition. Nephrol 2009, 2(12):9-10.

19. Ohta M, Babazono T, Uchigata Y, Iwamoto Y: Comparison of the prevalence of chronic kidney disease in Japanese patients with Type 1 and Type 2 diabetes. Diabet Med 2010, 27(9):1017-1023.

20. Janmohamed MN, Kallurya SE, Mueller A, Kabangila R, Smart LR, Downs JA, Peck RN: Prevalence of chronic kidney disease in diabetic adult out-patients in Tanzania. BMC Nephrol 2013, 14:183.

21. Middleton RJ, Foley RN, Hegarty J, Cheung CM, McElduff P, Gibson JM, Kalra PA, O'Donoghue DJ, New JP: The unrecognized prevalence of chronic kidney disease in diabetes. Nephrol Dial Transplant 2006, 21(1):88-92.

22. Myers GL, Miller WG, Coresh J, Fleming J, Greenberg N, Greene T, Hostetter T, Levey AS, Panteghini M, Welch M, Eckfeldt JH for the National Kidney Disease Education Program Laboratory Working Group: Recommendations for improving serum creatinine measurement: a report from the Laboratory Working Group of the National Kidney Disease Education Program. J Clin Chem 2006, 52(1):5-18.

23. Astor BC, Hallan SI, Miller ER III, Yeung E, Coresh J: Glomerular Filtration Rate, Albuminuria, and Risk of Cardiovascular and All-Cause Mortality in the US Population. Am J Epidemiol 2008, 167:1226-1234.

24. Poggio ED, Wang X, Greene T, Van Lente F, Hall PM: Performance of the modification of diet in renal disease and the Cockroft-Gault equations in the estimation of GFR in health and in chronic kidney disease. J Am Soc Nephrol 2005, 16:459-466.

25. Rigalleau V, Lasseur C, Perlemoine C, Barthe N, Raffaitin C, Liu C, Chauveau P, Baillet-Blanco L, Beauvieux MC: Estimation of glomerular filtration rate in diabetic subjects: Cockcroft formula or Modification of Diet in Renal Disease study equation? Diabetes Care 2005, 28:838-843.

26. Jesudason PC: Interpreting different measures of glomerular filtration rate in obesity and weight loss: pitfalls for the clinician. Int J Obes 2012, 36:1421-1427.

doi:10.1186/1471-2369-15-198

Cite this article as: Fiseha et al:: Chronic kidney disease and

underdiagnosis of renal insufficiency among diabetic patients attending a hospital in Southern Ethiopia. BMC Nephrology 2014 15:198. 